\title{
Pengaruh Suhu dan Intensitas Cahaya Terhadap Pertumbuhan Jamur Tiram di Tangerang
}

\author{
FENNY AMELIA ${ }^{1}$, JOSE FERDINAND $^{1}$, KLERENITA MARIA $^{1}$, \\ MICHEL GEREN WALUYAN ${ }^{1}$, INDAH JUWITA SARI ${ }^{2}$ \\ ${ }^{1}$ Program Studi Bioteknologi dan Neurosains, Fakultas Ilmu Hayati, \\ Universitas Surya Kampus Hub \\ J1. Gading Serpong Boulevard Blok M5 No. 21 Tangerang, Banten, Jawa Barat. 15810 \\ ${ }^{2}$ Pendidikan Biologi, Fakultas Keguruan dan Ilmu Pendidikan, Universitas Sultan Ageng Tirtayasa \\ Jl. Ciwaru Raya Serang, Banten, Jawa Barat. 42117 \\ email: indah.juwitasari@gmail.com
}

\begin{abstract}
Oyster mushroom is a mushroom that can be consumed, because it contains many nutrients such as vitamins, minerals, and amino acid. Nowadays, demand for oyster mushroom in Indonesia continues to increase, especially in the lowland like Tangerang. Knowing this, it needs effort to control the habitat that oyster mushrooms can be cultivated. This research was conducted by giving three treatments where the first treatment directly using sun light, the second treatment using a lamp with 5 watts power, and a third treatment using a lamp with 15 watts power. The data obtained are progress of baglog and temperature measurements in each treatment and then the data were analyzed using ANOVA test. With 5\% significance level, research results between treatments using direct sunlight with the light from the lamp gives a significantly different effect, while between a lamp with 5 watt power and a lamp with 15 watt power do not give a significantly different effect. Best oyster mushroom growth obtained at treatment using a lamp with 5 watts power.
\end{abstract}

Keywords: cultivation, light intensity, oyster mushroom, Tangerang, temperature

\section{INTISARI}

Jamur tiram merupakan jamur yang dapat dikonsumsi, karena mengandung banyak nutrisi seperti vitamin, mineral dan asam amino. Saat ini, permintaan jamur tiram di Indonesia terus meningkat khususnya di wilayah yang rendah seperti Tangerang. Mengetahui hal tersebut, diperlukan usaha pengendalian habitat agar jamur tiram dapat dikultivasi. Penelitian ini dilakukan dengan memberikan 3 perlakuan dimana pada perlakuan pertama menggunakan cahaya matahari secara langsung, perlakuan kedua menggunakan lampu berdaya 5 watt, dan perlakuan ketiga menggunakan lampu berdaya 15 watt. Data yang diperoleh adalah perkembangan baglog dari setiap perlakuan dan pengukuran suhu pada setiap perlakuan, kemudian data dianalisis menggunakan uji ANOVA. Hasil penelitian menunjukkan bahwa suhu yang dihasilkan pada perlakuan menggunakan cahaya matahari secara langsung dengan cahaya dari lampu memberikan pengaruh yang berbeda nyata, sedangkan antara lampu berdaya 5 watt dengan lampu berdaya 15 watt tidak memberikan pengaruh yang berbeda nyata terhadap suhu yang dihasilkan. Pertumbuhan jamur tiram terbaik didapatkan pada perlakuan dengan menggunakan lampu berdaya 5 watt.

Kata Kunci: intensitas cahaya, jamur tiram, kultivasi, suhu, Tangerang

\section{PENDAHULUAN}

Jamur tiram merupakan salah satu jenis jamur yang dapat dimakan. Kultivasi jamur tiram di dunia bahkan di Indonesia terus meningkat karena (1) kemampuan jamur tiram yang dapat tumbuh pada rentang suhu tertentu, (2) memanfaatkan berbagai limbah industri sebagai media pertumbuhan seperti serbuk kayu, ampas tebu, limbah kertas, daun dan lainnya, (3) merupakan jamur kayu yang paling mudah beradaptasi dengan lingkungannya, (4) jamur tiram dapat dipanen 
secara berlanjut, tidak dipengaruhi oleh musim, dan (5) jamur tiram mengandung banyak nutrisi yang dibutuhkan oleh manusia (Sharma, 2013 dan Suharjo, 2015).

Jamur tiram memiliki tubuh buah yang terdiri dari tudung dan tangkai. Tudung jamur tiram berbentuk seperti tiram dan bagian bawahnya berlapis seperti insang (Djarijah, 2011). Jamur tiram kaya akan vitamin, mineral dan asam amino (Vamanu, 2012). Kandungan lovastatin dalam jamur dapat menjaga kolesterol penderita hiperkolesterolemia. Selain itu, aktivitas hipolipidemik pada jamur tiram sebagai zat anti aterosklerosis (Alam et al., 2011).

Jamur tiram tidak hanya dimanfaatkan di wilayah sejuk seperti Bogor, tetapi banyak masyarakat di wilayah lain yang juga memanfaatkan jamur tiram khususnya di Tangerang. Kota Tangerang berada di wilayah yang rendah dan memiliki suhu yang cukup panas, sehingga diperlukan pengendalian habitat tempat jamur tiram tumbuh, seperti suhu dan intensitas cahaya yang mendekati habitat asli jamur tiram. Afief, Lahay dan Siagian (2015) melakukan penelitian mengenai jamur tiram di Medan dengan ketinggian kurang lebih 25 meter diatas permukaan laut.

Terdapat sedikit penelitian mengenai budidaya jamur tiram di wilayah rendah, terutama mengenai pengaruh suhu dan intensitas cahaya. Oleh karena itu, peneliti melakukan penelitian mengenai pengaruh suhu dan intensitas cahaya terhadap pertumbuhan jamur tiram di wilayah Tangerang.

Penelitian mengenai pengaruh suhu terhadap pertumbuhan jamur tiram juga pernah dilakukan oleh Putranto dan Yamin (2012) dengan karung goni basah, dimana terdapat perbedaan pertumbuhan buah jamur tiram dan mempengaruhi produktivitas jamur tiram.

Penelitian ini bertujuan untuk mengetahui pengaruh suhu dan intensitas cahaya terhadap pertumbuhan jamur tiram di wilayah Tangerang sehingga dapat menghasilkan jamur tiram dengan mudah tanpa mengurangi kandungan gizi dan nutrisi dari jamur tiram. Intensitas cahaya yang diteliti menggunakan lampu putih berdaya 5 watt dan 15 watt.

\section{METODE}

Penelitian dilakukan di teras rumah salah satu peneliti di Jalan Wisma Lantana Blok c1 nomor 56, Tangerang, Banten 15133. Penelitian ini terdiri dari tiga perlakuan intensitas cahaya, yaitu tanpa lampu, dengan lampu berdaya 5 watt dan lampu berdaya 15 watt. Setiap perlakuan menggunakan 3 Baglog dan dilakukan pengulangan sebanyak dua kali. Jumlah Baglog yang digunakan sebanyak 18 Baglog. Penyinaran dengan lampu dilakukan selama 24 jam setiap harinya. Baglog tanpa lampu hanya mendapatkan pencahayaan dari sinar matahari. Setiap Baglog mendapat perlakuan yang sama dalam penyiraman, dan kelembaban. Penyiraman dilakukan setiap dua kali sehari, pagi dan sore hari. Pada dasar kardus, diletakkan baki berisi air yang berfungsi untuk menjaga kelembaban. Baglog diletakkan di atas kayu, sehingga Baglog tidak bersentuhan langsung dengan air. Tiga perlakuan yang berbeda diletakkan pada tiga kardus yang berbeda.

Pengukuran suhu dilakukan setiap hari dan perkembangan dari jamur tiram diamati setiap dua hari sekali. Data yang diperoleh berupa suhu yang dihasilkan berdasarkan intensitas cahaya, berat tubuh buah jamur tiram. Untuk melihat pengaruh pemberian intensitas cahaya yang berbeda terhadap pertumbuhan jamur tiram menggunakan uji ANOVA dengan alfa 5\%. Data kemudian diolah dengan membandingkan hasil panen tubuh buah jamur tiram dengan perlakuan intensitas cahaya dan suhu.

\section{HASIL \\ Budidaya Pertama}

Tabel 1. Suhu setiap perlakuan kultivasi pertama

$\begin{array}{cccc}\text { Hari ke- } & \text { TL }\left({ }^{\circ} \mathrm{C}\right) & \text { L5W }\left({ }^{\circ} \mathrm{C}\right) & \text { L15W }\left({ }^{\circ} \mathrm{C}\right) \\ 2 & 28 & 30 & 30\end{array}$




\begin{tabular}{cccc}
\hline $\mathbf{3}$ & 27 & 29 & 29 \\
$\mathbf{4}$ & 27 & 28 & 29 \\
$\mathbf{5}$ & 27 & 29 & 28 \\
$\mathbf{6}$ & 27 & 28 & 29 \\
\hline $\mathbf{7}$ & 27 & 29 & 29 \\
\hline $\mathbf{8}$ & 27 & 29 & 29 \\
\hline $\mathbf{9}$ & 27 & 28 & 28 \\
\hline $\mathbf{1 0}$ & 27 & 29 & 29 \\
\hline $\mathbf{1 1}$ & 28 & 29 & 30 \\
\hline $\mathbf{1 3}$ & 28 & 29 & 31 \\
\hline $\mathbf{1 4}$ & 28 & 30 & 30 \\
\hline $\mathbf{1 5}$ & 27 & 28 & 30 \\
\hline $\mathbf{1 6}$ & 27 & 29 & 30 \\
\hline Rata-rata & 25 & 27 & 28 \\
\hline
\end{tabular}

Ket.

TL: Tanpa Lampu (Penyinaran langsung dari cahaya matahari); L5W: Lampu 5 Watt; L15W: Lampu 15 Watt

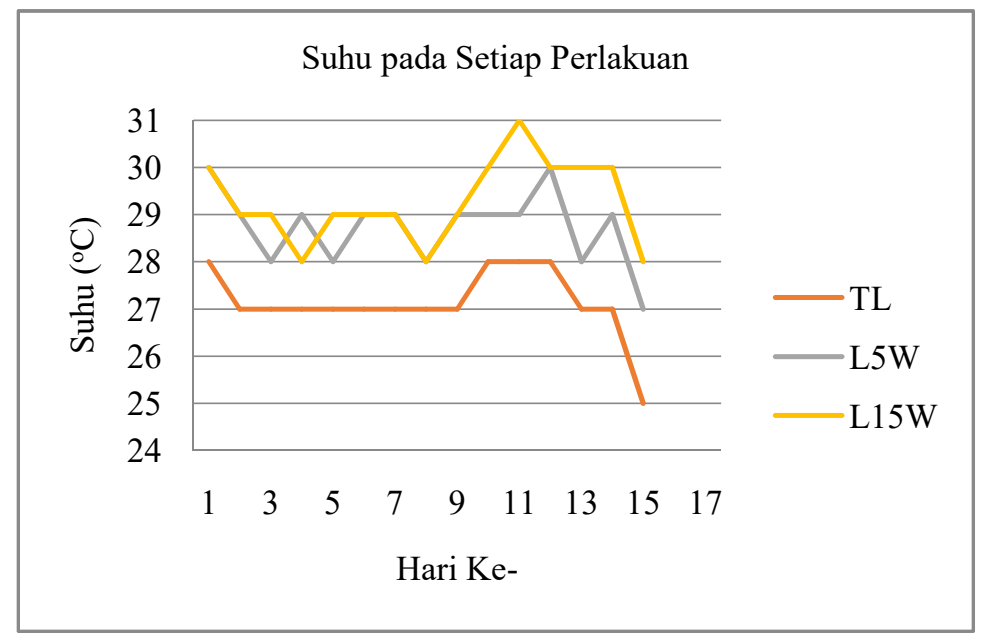

Gambar 1. Suhu setiap perlakuan pada kultivasi pertama

Gambar 1 menunjukkan suhu masa budidaya jamur tiram pertama. Terdapat tiga garis pada grafik. Garis TL berarti perlakuan tanpa lampu, garis L5W berarti perlakuan dengan lampu 5 watt, dan garis L15W berarti perlakuan dengan lampu 15 watt.

\section{Budidaya Kedua}

Tabel 2. Suhu setiap perlakuan kultivasi kedua

\begin{tabular}{cccc}
\hline Hari Ke- & TL $\left({ }^{\mathbf{}} \mathbf{C}\right)$ & L5W $\left({ }^{\mathbf{0}} \mathbf{C}\right)$ & L15W $\left({ }^{\mathbf{0}} \mathbf{C}\right)$ \\
\hline $\mathbf{1}$ & 27 & 29 & 29 \\
$\mathbf{2}$ & 27 & 29 & 30 \\
\hline $\mathbf{3}$ & 27 & 30 & 30 \\
\hline $\mathbf{4}$ & 27 & 30 & 29 \\
\hline $\mathbf{5}$ & 27 & 30 & 31 \\
\hline $\mathbf{6}$ & 28 & 30 & 30 \\
\hline $\mathbf{7}$ & 28 & 30 & 31 \\
\hline $\mathbf{8}$ & 29 & 30 & 30 \\
\hline $\mathbf{9}$ & 28 & 30 & 30 \\
\hline $\mathbf{1 0}$ & 28 & 31 & 31 \\
\hline $\mathbf{1 1}$ & 29 & 30 & 30 \\
\hline
\end{tabular}




\begin{tabular}{cccc}
\hline $\mathbf{1 2}$ & 27 & 30 & 30 \\
\hline $\mathbf{1 3}$ & 29 & 30 & 31 \\
\hline $\mathbf{1 4}$ & 28 & 31 & 31 \\
\hline $\mathbf{1 5}$ & 27 & 30 & 30 \\
\hline $\mathbf{1 6}$ & 30 & 30 & 30 \\
\hline Rata-rata & 27,87 & 30,00 & 30,18 \\
\hline
\end{tabular}

Keterangan:

TL: Tanpa Lampu (Penyinaran langsung dari cahaya matahari); L5W: Lampu 5 Watt; L15W: Lampu 15 Watt

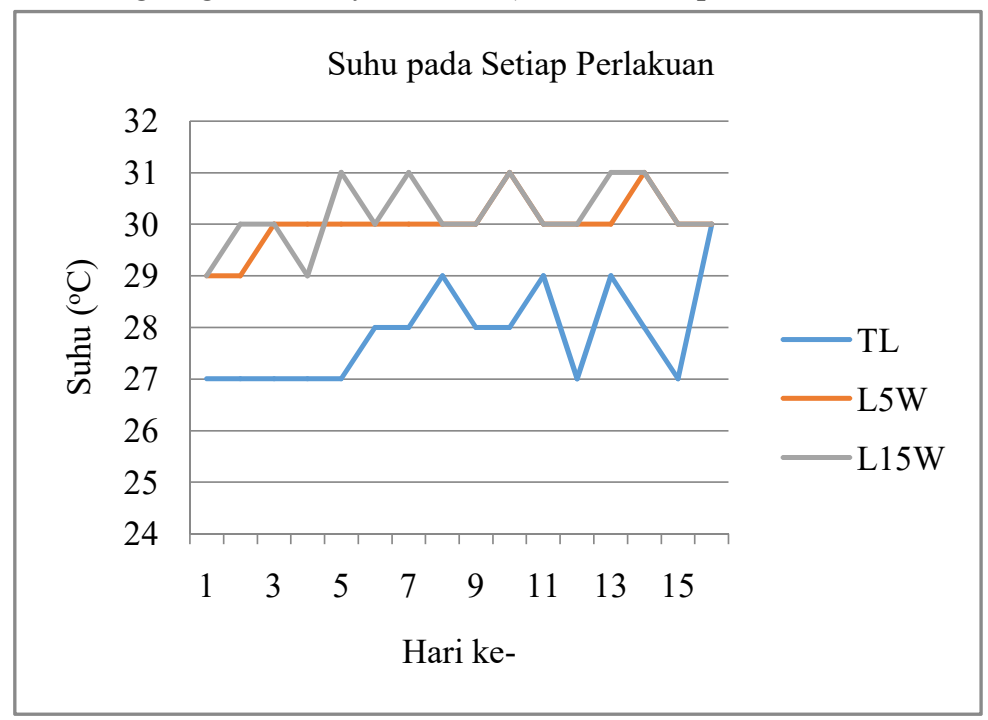

Gambar 2. Suhu setiap perlakuan pada kultivasi kedua

Gambar 2 menunjukkan suhu masa budidaya jamur tiram kedua. Terdapat tiga garis pada grafik. Garis TL berarti perlakuan tanpa lampu, garis L5W berarti perlakuan dengan lampu 5 watt, dan garis L15W berarti perlakuan dengan lampu 15 watt. Pada grafik, sumbu $x$ menyatakan hari ke-, dan pada sumbu $y$ menyatakan suhu pada setiap perlakuannya.

\section{PEMBAHASAN}

Budidaya Pertama. Perlakuan tanpa cahaya lampu menghasilkan suhu yang lebih kecil dibandingkan dengan perlakuan lainnya. Rata-rata suhu yang dihasilkan pada perlakuan tanpa cahaya lampu sebesar $27,87^{\circ} \mathrm{C}$ dengan suhu tertinggi $28^{\circ} \mathrm{C}$, sedangkan perlakuan dengan penyinaran lampu 5 watt dan 15 watt menghasilkan ratarata suhu lebih tinggu, yaitu $30^{\circ} \mathrm{C}$ dan $30,18^{\circ} \mathrm{C}$ dan suhu tertinggi mencapai $30^{\circ} \mathrm{C}$ dan $31^{\circ} \mathrm{C}$. Hal ini terjadi karena penambahan intensitas cahaya dengan lampu menghasilkan panas sehingga meningkatkan suhu di sekitar kumbung. Dengan level signifikansi 5\% (tingkat kepercayaan 95\%) perlakuan menggunakan cahaya dari lampu dan cahaya matahari secara langsung memberikan pengaruh yang signifikan terhadap suhu dan pertumbuhan jamur tiram terlihat dari hasil perhitungan dengan uji ANOVA, hasil $\mathrm{F}$ hitung $(28,14)$ lebih besar dari F tabel $(3,22)$.

Bila membandingkan pertumbuhan jamur tiram yang diberi cahaya lampu 5 watt dengan cahaya lampu 15 watt, keduanya tidak memberikan pengaruh yang berbeda nyata terhadap suhu dan pertumbuhan jamur tiram, terlihat dari hasil perhitungan dengan uji ANOVA, dengan level signifikansi 5\% hasil F hitung $(3,007)$ lebih kecil dari F tabel $(4,2)$. Dengan baglog yang diberikan pencahayaan dari sinar matahari secara langsung tidak menghasilkan tubuh jamur tiram. Pada hari ketiga, baglog yang diberikan cahaya lampu 5 watt tumbuh tubuh buah jamur tiram dan pada hari keenam jamur tiram dipetik dan memiliki berat 0,342 gram.

Pada baglog yang diberikan cahaya lampu 15 watt tumbuh hama jamur tiram, yaitu jamur tinta (Gambar 3). Jamur tinta berasal dari filum Basidiomycota (Reyes et al., 2009) memiliki bahasa latin Coprinus sp. 
Tubuh buah jamur tinta tumbuh dengan cepat dan akan menjadi tinta dengan sendirinya

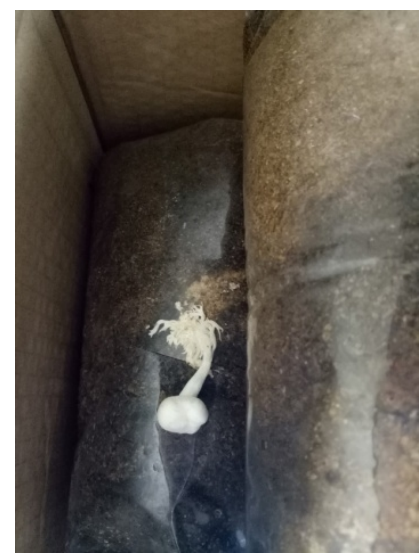

A karena memiliki kemampuan autolisis (Reyes et al., 2009).

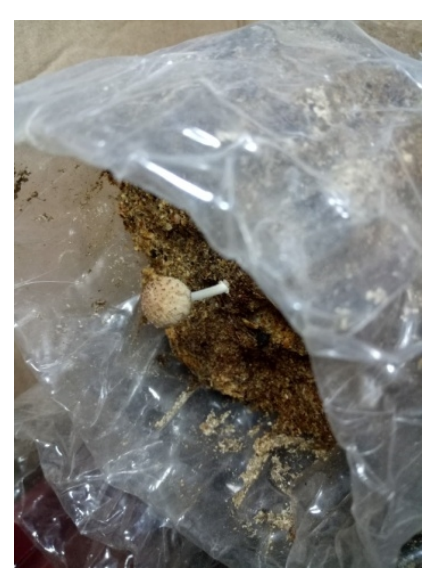

$\mathrm{B}$

Gambar 3. Jamur tiram tumbuh pada perlakuan yang diberikan cahaya lampu 5 watt pada hari ke empat (A); Jamur tinta tumbuh pada perlakuan yang diberikan cahaya lampu 15 watt pada hari ke sembilan (B).

Budidaya Kedua. Pemberian cahaya lampu menghasilkan suhu yang lebih tinggi daripada tanpa pemberian cahaya (langsung dari sinar matahari). Rata-rata suhu pada perlakuan tanpa lampu sebesar $27,87^{\circ} \mathrm{C}$ dengan suhu tertinggi mencapai $30^{\circ} \mathrm{C}$, perlakuan kedua menggunakan penyinaran lampu 5 watt sebesar $30^{\circ} \mathrm{C}$ dan perlakuan ketiga sebesar $30,18^{\circ} \mathrm{C}$ dengan suhu tertinggi $31^{\circ} \mathrm{C}$. Dengan tingkat kepercayaan $95 \%$, perlakuan tanpa lampu dengan adanya cahaya lampu memberikan pengaruh signifikan terhadap suhu dan pertumbuhan jamur tiram.

Hasil uji ANOVA menunjukkan F hitung $(49,109)$ lebih besar dari dari F tabel $(3,20)$. Perlakuan pemberian cahaya lampu 5 watt dan 15 watt tidak menghasilkan perbedaan suhu yang signifikan, terlihat dari hasil uji ANOVA, dengan tingkat kepercayaan $95 \% \mathrm{~F}$ hitung $(0,808)$ lebih kecil dari pada $F$ tabel $(4,17)$. Selama 16 hari masa budidaya, ketiga perlakuan tidak menghasilkan jamur tiram maupun jamur tinta.

\section{KESIMPULAN}

Pemberian perbedaan intensitas cahaya dan suhu menunjukkan adanya pengaruh terhadap pertumbuhan jamur tiram (Pleurotus ostreatus). Hasil terbaik berada pada suhu $\pm 28^{\circ} \mathrm{C}$ dengan pencahayaan menggunakan lampu sebesar 5 watt. Pencahayaan menggunakan lampu sebesar 15 watt dengan suhu $\pm 29^{\circ} \mathrm{C}$ ditumbuhi dengan baik oleh jamur tinta (Coprinus sp.).

\section{UCAPAN TERIMA KASIH}

Peneliti sangat berterima kasih kepada Ibu Indah Juwita Sari, M.Si selaku dosen pembimbing yang bersedia memberikan materi dan arahan dalam penelitian ini.

\section{DAFTAR PUSTAKA}

Alam N, Yoon KN, Lee TS, Lee UY. 2011. Hypolipidemic Activities of Dietary Pleurotus ostreatus in Hypercholesterolemic Rats. Mycrobiology. vol 39(1): 45-51.

Afief FM, Lahay RR, Siagian B. 2015. Respon Pertumbuhan dan Produksi Jamur Tiram Putih (Pleurotus ostreatus) Terhadap Berbagai Media Serbuk Kayu dan Pemberian Pupuk NPK. Jurnal Online Agroekoteknologi. vol 3(4): 13811390.

Djarijah MN, Djarijah BA. 2011. Budi Daya Jamur Tiram Pembibitan Pemeliharaan dan Pengendalian Hama-Penyakit. Yogyakarta: Kanisius.

Putranto AM, Yamin M. 2012. Pengendalian Suhu Ruang pada Budidaya Jamur Tiram 
dengan Karung Goni Basah. Jurnal Keteknikan Pertanian. vol 26(2): 137142.

Reyes GR, A.Lopez LLM, Kumakura K, KalawSP, Kikukawa T, Eguchi F. 2009. Coprinus comatus, a Newly Domesticated Wild Nutriceutical Mushroom in the Phillipines. Journal of Agricultural Technology. vol 5(2): 299316.

Sharma S, Yadav PKR, Pokhrel PC. 2013. Grown and Yield of Oyster Mushroom
(Pleurotus ostreatus) on Different Subtrates. Journal on New Biological Reports. vol 2(1): 03-08.

Suharjo E. 2015. Budidaya Jamur Tiram Media Kardus. Jakarta: PT Agromedia Pustaka.

Vanamu E. 2012. Biological Activities of the Polysaccharides Produced in Submerged Culture Two Edible Pleurotus ostreatus Mushrooms. Journal of Biomedicine and Biotechnology.

http://dx.doi.org/10.1155/2012/565974. 